\title{
IDENTIFICATION OF NEW MOLECULAR BIOMARKERS - PROTEOMICS
}

\author{
Slađana Vujačić \\ Institute for Emergency Medical Services, Podgorica, Montenegro
}

Primljen/Received 03. 03. 2018. god.

Abstract: The pathogenesis of the tumor is extremely complex and can not be fully explained by the existing methodological approaches. Proteomics is an interdisciplinary science that deals with the study of proteins, carriers of the biological functions of the organism. It encompasses a series of methods for protein analysis and provides exceptional possibilities for understanding the molecular basis of the disease, the possibilities of early diagnosis, and the production of new drugs. Proteomic analyzes of the malignancy altered tissue have revealed proteins involved in the progression of the disease, and thus contributed to the discovery of potential drug treatment methods. Proteomics provides a better understanding of the molecular basis of these diseases, plays a role in the diagnosis of the same, and it is expected to make a significant contribution to the development of new more effective drugs and the development of personalized therapy.

Key words: proteomics, proteins, biomarkers, tumors.

\section{IDENTIFICATION OF NEW MOLECULAR BIOMARKERS - PROTEOMICS}

The pathogenesis of the tumor is extremely complex and it is not possible to fully clarify it with existing methodological approaches. It is therefore extremely important to get a more accurate knowledge of the molecular basis of this disease. Understanding changes at protein level represents a step closer to understanding tumor pathogenesis (1).

Different parts of the protein are accumulated in the exocomes of lung cancer cells that could be used for the early diagnosis of this cancer.

Jakobsen et al. reported that CD317 and epidermal growth factor receptor (EGFR) were highly expressed on exosomal surface, by analyzing the extracellular vesicles secreted by lung cancer cells. These molecules are reliable biomarkers for diagnosing
Prihvaćen/Accepted 29. 03. 2018. god.

non-small cell lung cancer (NSCLC). Research has shown that human leucine rich alpha-2-glycoprotein 1 (LRG1) in urinary exosomes was a potential biomarker for diagnosing NSCLC. Sandfeld et al. used 49 antibodies to detect exosomal proteins from 431 lung cancer patients and 150 healthy individuals. They found that CD171, CD151 and tetraspanin 8 were significantly highly expressed in patients as compared to healthy individuals. In squamous-cell carcinoma and small-cell lung cancer patients, CD151 is also an independent biomarker. Recently, exosomes in peripheral blood were reported to contain 30 specific biomarkers.

Latent membrane protein 1 (LMP1) in exosomes from nasopharyngeal cell lines infected with Epstein Barr virus (EBV), nasopharyngeal cancer cells could release HLA II and exosomes containing galectin 9 and/or LMP1. LMP1 could inhibit T cell viability. Klibi et al. found exosomes carrying LMP1 in blood and saliva from the nasopharynx of cancer patients. Houali et al. detected LMP1 and BARF1 coded by EBV in serum and saliva from teenagers and adults, and in adult nasopharyngeal cancer patients' serum and saliva at $62 \%$ and $100 \%$, respectively. Animal experiments demonstrated that LMP1 secretion was related to exosomes. Both proteins were good markers for nasopharyngeal cancer diagnosis, especially BARF1, because it covered the entire age range. Their pro-mitotic activities facilitated the occurrence and development of nasopharyngeal cancer. Cancer exosomes could be continuously detected in the plasma of nasopharyngeal cancer patients. The increase in serum exosomal concentration of nasopharyngeal cancer patients was closely related to terminal-stage lymphatic metastasis and poor prognosis.

Glypican-1 (GPC1)-positive exosome is a diagnostic index of early stage pancreatic cancer. Circulating exosomes containing GPC1 (GPC1 + Exos) were isolated from blood of 250 pancreatic cancer patients, which helped to distinguish between chronic pancreatitis and pancreatic cancer patients. In animal experi- 
ments, GPC1 + Exos in blood were significantly increased, before cancer imaging could be used. GPC1-positive exosomes could also be used as a preoperative and postoperative prognostic index. GPC1 + Exos was a significantly better prognostic marker of pancreatic cancer than CA19-9. Thus, GPC1 + Exos could be used to diagnose pancreatic cancer at early and terminal stages with high accuracy and sensitivity, and as a detection index for therapy. Macrophage migration inhibitory factor (MIF) was found to promote hepatic metastasis of cancers, and could be used as an early stage diagnostic marker for pancreatic cancer hepatic metastasis.

A mouse liver damage model was established to analyze urinary exosomal proteomics. Twenty-eight novel exosomes closely related to disease were found, in which CD26, CD81, S1C3A1 and CD10 could be used as markers for hepatic damage. In cholangiocarcinoma model caused by Opisthorchis viverrini, 154 proteins were disrupted after cancer onset. To find the specific marker for diagnosing cholangiocarcinoma caused by Opisthorchis viverrini in circulating body fluids, exosomes from peripheral circulation of patients were extracted and compared with those from cholangiocarcinoma cell line KKU055. Finally, 27 specific proteins were identified, which provided an experimental basis for cholangiocarcinoma diagnosis.

In gastric cancer exosomes play an important function in the interaction between cancer cells, the vascular endothelial cells and the macrophages. Exosomes derived from gastric cancer cells could also stimulate the activation of the NF-kB pathway in macrophages to promote cancer progression . Recent evidence has found that AZ-P7a, a metastatic gastric cancer cell line, released let-7 miRNAs via exosomes into the extracellular environment to maintain the oncogenesis. The enrichment of let-7 miRNA family in the exosomes from AZ-P7a cells may reflect metastasis in gastric cancer. CD97 promotes gastric cancer cell proliferation and invasion in vitro through exosomes-mediated MAPK signaling pathway, and exosomal miRNAs are probably involved in the activation of the CD97-associated pathway. the $\mathrm{Cbl}$ family of ubiquitin ligases might be involved in regulation of exosome-induced apoptosis of Jurkat $\mathrm{T}$ cells by increasing PI3K proteasome degradation, inactivation of PI3K/ Akt signaling, thus mediating some effects of caspase activation.. The role of tetraspanin 8-containing exosomes is associated with cell growth and invasion in GC; tetraspanin 8 is an inependent prognostic factor in patients with gastric cancer. Gastric cancer cells triggered the differentiation of human umbilical cordderived mesenchymal stem cells to carcinoma-associated fibroblasts by exosomes-mediated TGF- $\beta$ transfer and activation of the
TGF- $3 /$ Smad pathway, which may represent a novel mechanism for MSCs-to- CAFs transition in cancer. Furthermore, the $\mathrm{Cbl}$ family of ubiquitin ligases might be involved in regulation of exosome-induced apoptosis of Jurkat $\mathrm{T}$ cells by increasing PI3K proteasome degradation, inactivation of $\mathrm{PI} 3 \mathrm{~K} /$ Akt signaling, thus mediating some effects of caspase activation. Exosomes derived from human mesenchymal stem cells promote gastric cancer cell growth and migration via induction of the epithelial-mesenchymal transition and the activation of the Akt pathway. CD97 promotes gastric cancer cell proliferation and invasion in vitro through exosomes-mediated MAPK signaling pathway, and exosomal miRNAs are probably involved in the activation of the CD97-associated pathway. The role of tetraspanin 8-containing exosomes is associated with cell growth and invasion in GC; tetraspanin 8 is an independent prognostic factor in patients with gastric cancer. Additionally, TEX may play a critical role in the development of peritoneal metastases of gastric cancer, which may partially be due to the increased expression of the adhesion molecules fibronectin 1 (FN1) and laminin gamma 1 (LAMC1) in mesothelial cells. Baran et al. found that the number of exosomes was significantly higher in gastric cancer patients than in the normal control group. Expressions of human epidermal growth factor receptor (HER-2/neu) and human chemokine receptor-6 (CCR6) were significantly increased on exosomal surface in blood. Cancer markers such as HER-2/neu, melanoma antigen (MAGE) and c-Met as well as extracellular matrix metalloproteinase inducer (EMMPRIN) could be detected in exosomes from normal controls and gastric cancer patients. However, the patients expressed higher levels of these markers, of which MAGE-1 and HER-2/neu mRNA had significantly higher expression in exosomes from gastric cancer patients. Adenomatous polyposis coli (APC) mutation was found in early stage colorectal cancer, invisible chromosome familiar adenomatous polyposis and most sporadic colorectal cancers, and might lead to its occurrence and development. Comparison between SW480 cells transfecting APC gene plasmid and exosomal proteome secreted by SW480 cells showed that dickkopf-related protein 4 (DKK 4) was highly expressed in exosomes of SW480 cells transfecting APC gene plasmid. In these cells, methylation level of DKK 4 gene promoter was decreased, suggesting that colorectal epithelial cells might up-regulate DKK 4 transcription and expression by down-regulating methylation of DKK 4 gene promoter, and further promote occurrence and development of colorectal cancer by exosomes secreting DKK 4 and inducing APC gene mutation. The comparison of exosomal proteome between KRAS wild type DKS- 8 cells of human 
colon adenocarcinoma cells DLD-1 and K-RAS mutant type DKO-1 cells indicated that DKS-8 secreted by DKO-1 exosomes was not only significantly proliferated but its invasion capacity was also increased. These experiments demonstrated that colorectal cancer exosomes played a critical role in maintaining cancer cell survival, proliferation and invasion of microenvironment. Silva et al. quantitatively detected plasma exosomes from 91 colorectal cancer patients and found that the number of exosomes was significantly higher than in the control group, and also significantly correlated with carcinoembryonic antigen (CEA). Plasma exosomes in colorectal cancer patients can be used as a cancer marker that is closely related to disease development and poor prognosis (2)

Some of the biomarkers used in clinical work (diagnostic, predictive, prognostic and biomarkers for disease monitoring) are shown in Tables 1-4 (2, 3).

Table 1. Diagnostic biomarkers

\begin{tabular}{|c|c|c|}
\hline \multirow{8}{*}{ Acute leukemia } & \multicolumn{2}{|l|}{ PML-RARA } \\
\hline & \multicolumn{2}{|l|}{ BCR-ABL1 } \\
\hline & \multicolumn{2}{|l|}{ CBFB-MYH11 } \\
\hline & \multicolumn{2}{|l|}{ ETV6-RUNX1 } \\
\hline & \multicolumn{2}{|l|}{ RUNX1-RUNX1T1 } \\
\hline & \multicolumn{2}{|l|}{ MLL-rearranged } \\
\hline & \multicolumn{2}{|l|}{ TCF3-PBX1 } \\
\hline & \multicolumn{2}{|l|}{ RBM15-MKL1 } \\
\hline MPD & \multicolumn{2}{|l|}{ JAK2 } \\
\hline \multirow{10}{*}{ Sarcoma } & SS18-SSX1/SSX2 & Synovial sarcoma \\
\hline & PAX3/PAX7-FOXO1A & Alveolar rhabdomyosarcoma \\
\hline & $\begin{array}{l}\text { EWSR1-FLI1 } \\
\text { EWSR1-ERG }\end{array}$ & Ewing's sarcoma \\
\hline & $\begin{array}{l}\text { EWSR1-NR4A3 } \\
\text { TAF15-NR4A3 }\end{array}$ & Extraskeletal myxoid chondrosarcoma \\
\hline & $\begin{array}{l}\text { EWSR1-ATF1 } \\
\text { EWSR1-CREB1 }\end{array}$ & Clear cell sarcoma and angiomatoid fibrous histiocytoma \\
\hline & ASPSCR1-TFE3 & $\begin{array}{l}\text { Alveolar soft-part } \\
\text { Sarcoma and renal cell carcinoma }\end{array}$ \\
\hline & FUS-DDIT3 & Myxoid liposarcoma \\
\hline & FUS-CREB3L2 & Low-grade fibromyxoid sarcoma \\
\hline & JAZF1-SUZ12 & Endometrial stromal sarcoma \\
\hline & ETV6-NTRK3 & Congenital fibrosarcoma and secretory breast carcinoma \\
\hline
\end{tabular}

Table 2. Predictive biomarkers

\begin{tabular}{|c|c|l|}
\hline \multirow{2}{*}{ NSCLC } & EGFR & Mutations predict response to TKI \\
\cline { 2 - 3 } & ALK & Rearrangements predict response to ALK-inhibitors \\
\hline GIST & KIT and PDGFRA & Mutations predict response to c-KIT/PDGFRA inhibitors \\
\hline mCRC & KRAS & Mutations predict lack of response to anti-EGFR antibodies \\
\hline Melanoma & BRAF & Mutations predict response to specific BRAF inhibitors \\
\hline Breast cancer & HER2 & Amplifications predict response to anti-HER2 antibodies \\
\hline
\end{tabular}

Table 3. Prognostic biomarkers

\begin{tabular}{|l|l|l|}
\hline CLL & $\begin{array}{l}\text { TP53 } \\
\text { IGHV }\end{array}$ & $\begin{array}{l}\text { Mutations are indicative of poor outcome } \\
\text { Lack of mutations is indicative of poor outcome }\end{array}$ \\
\hline AML & FLT-3-ITD & Mutations are indicative of poor outcome \\
\hline mCRC & BRAF & Mutations are indicative of poor outcome \\
\hline Breast cancer & $\begin{array}{l}\text { OncotypeDx } \\
\text { Mammaprint } \\
\text { IHC4 }\end{array}$ & $\begin{array}{l}\text { Risk stratification (21-gene expression signature) } \\
\text { Risk stratification (70-gene expression signature) } \\
\text { Risk stratification (4-protein IHC expression) }\end{array}$ \\
\hline
\end{tabular}


Table 4. Biomarkers for disease monitoring

\begin{tabular}{|c|l|l|}
\hline CML & BCR-ABL1 & Minimal residual disease detection \\
\hline APML & PML-RARA & Minimal residual disease detection \\
\hline ALL & IGHV-TCR rearrangements & Minimal residual disease detection \\
\hline
\end{tabular}

Proteomics is an interdisciplinary science that deals with the study of proteins, carriers of the biological functions of the organism. It encompasses a series of methods for protein analysis and provides exceptional possibilities for understanding the molecular basis of the disease, the possibilities of early diagnosis, and the production of new drugs. The task of proteomics is extremely complex and includes the monitoring of the status of a proteome that represents a set of all proteins and protein forms that the body produces throughout life. Although it has been estimated that the total number of genes is close to 30.000 , the entire human protease consists of several million types of proteins due to various modifications of the RNA transcript and chemical modifications of the proteins themselves (4).

Proteins as molecular effectors of biological processes play an important role in the pathogenesis of the disease, and it is precisely the detection of proteins that are associated with a certain disease that is a step towards diluting the disease. Proteomics methods allow simultaneous monitoring of several thousand different proteins and their isoforms. The modified protein can enter into new interactions with other molecules with which another normal protein chemically does not react. The importance of viral oncogens is known, namely cells modified by the input of viral genes often exhibit new virus-associated antigens that can recognize the immune system. Oncogenic viruses are DNA or RNA type depending on the genetic information carried by the intact virus. It has been found that several human DNAs contain potential oncogenes and are associated with malignancy (e.g., Epstein - Barr virus and nasopharyngeal carcinoma, Burkitt lymphoma and Hodgicon lymphoma, a link between HPV and cervical, anorectal and cutaneous carcinoma). Both viral and cellular oncogenes in certain situations can lead to the transformation of the normal cell. Cellular oncogenes encode a range of proteins that can be normal or altered structures, such as cellular enzymes (protein kinases), nucleic and membrane proteins, making the cell's malignant immunologically different from the normal cell (5).

The molecular basis of the disease can not be understood only by studying the gene, but it is necessary to analyze the genetic protein products. Signal pathways in which proteins are involved have been altered in tumor cells, which confirms that protein analysis can provide an answer to the pathogenesis of the disease $(6,7)$.
The expression of the gene or protein expression provides the possibility of classifying the tumor. However, gene studies follow the level of information RNA expression where the strength of gene expression does not always correspond to the protein expression. Proteomics research provides more important information in understanding the mechanisms of protein activation and posttranslational changes that are responsible for the tumor cell phenotype and the processes that occur in them (1).

Using the proteomics method want:

- determine the difference in the expression profile between the individual groups, and determine which proteins are differently expressed between these groups (e.g., the difference in the expression profile between the histological tumor subtypes or the identification of proteins whose level is disrupted by cell exposure to the effect of a new experimental drug)

- determine the subgroup of proteins in a sample with respect to the expression pattern

(for example, the discovery of an unknown lymphoma subspecies based on an espression profile certain groups of gene)

- anticipate the phenotype using information obtained from the expression of the expression profile (for example, in which patient a severe symptomatology will be experienced after using a drug, or which patients with a breast tumor diagnosis and "negative" lymph nodes will experience relapses after two years of illness (4).

Characteristics of proteins, such as their complex nature and variability, require the development of a very sensitive and selective technology that will allow simultaneous analysis of thousands of proteins. The function of the protein depends on a number of different factors, such as the level of expression, posttranslational modification, interactions with other proteins or DNA / RNA molecules, mechanisms of activation and repression. The expression of protein in the biological composition changes with the stage of development, by the action of the environmental factors, disease progression, and the number of proteins in the eukaryotic cell is high. In molecular medicine, several modern proteomic techniques are available that enable the exploration of protein expression, protein modification analysis, cellular location analysis, and protein interaction monitoring. The disadvantages of proteomic methods are that proteomics are sometimes quite compli- 
cated and time-consuming technology. There is also a need for further improvement of proteomic methods in order to find a link between genes, proteins and the onset of disease, improvement of methods in the detection and characterization of proteins, both in the field of analysis of low molecular weight proteins and peptides (below $500 \mathrm{Da}$ ), as well as in the field of analysis of extremely large protein structure (above $120 \mathrm{kDa}$ ), and in improving quantification (8).

\section{METHODOLOGY OF PROTEIN RESEARCH}

The methodology of protein research uses a classical approach based on gel analysis ("shotgun" approach) using immobilized $\mathrm{pH}$ gradients by which proteins are separated based on their isoelectric points. Then, separation in the second dimension based on the molecular weight by using sodium dodecyl sulfate polyacrylamide gel electrophoresis, the gel provides a number of points representing proteins, various isoforms of the same protein or its posttranslational modification. Following the separation of the proteins on the gels, the identification of the separated and quantified proteins on the mass spectrometer is followed. In this way, the expression and type of proteins in the patient can be determined in relation to the healthy tissue.

MALDI-TOF (matrix-assisted laser desorption ionization time of flight) is a method for identifying proteins derived from the gel, based on the principle of degradation of each protein with the help of trypsin and their ionization. Thereafter, a comparison of the mass of the fragments with the spectra found in the database is performed, and thus the type of protein is determined.

In the analysis of ESI-MS / MS (electrospray ionization tandem mass spectrometry), the sample is ionised in the form of fine spray spray, after evacuation into the vacuum the water is evaporated and the molecules in the solution take up the charge. In contrast to the MALDI analysis, the molecular ions in the ESI-MS / MS analysis are generally multiply charged. The ESI-MS / MS analysis analyzes the samples in liquid state, and this method is often associated with high performance liquid chromatography (HPLC). The combination of HPLC and ESI-MS / MS is basically a "shotgun" approach that involves the isolation of hundreds of proteins from extremely complex mixtures obtained by proteolytic protein breakdown (eg in body fluids), followed by MS sequencing. This LC-MS / MS (liquid chromatography MS / MS) method is better than the classic proteomic approach. Namely, the LC-MS / MS method allows the separation and identification of analytes in the low femtolomolar range so that a large part of the biomarker detection research will be carried out in this way.
MudPIT (multidimensional protein identification technology), ICAT (isotope-coded affinity tags) and ICPL (isotope-coded protein labels) are also important "shotgun" techniques.

MudPIT is a method for identifying proteins from complex mixtures. The MudPIT method is based on a chromatographic separation of the protein in two dimensions, so that the proteins are first separated on the basis of the charge in the SCX column (strong cation exchange column), followed by reversed chromatography by which the peptides are separated based on their lipophilicity. This method is compatible with the ESI method in which its advantage is reflected.

ICAT and ICPL methods are based on the labeling of light and heavy isotope proteins in two analyzed samples. Subsequently, by means of mass spectrometry, the relative amount of the labeled molecules is determined based on the mass of the stable isotope used, such as carbon isotope. Thus, quantitative changes can be made in protein cells induced by some disease or therapeutic procedure.

Also, there is an ongoing tendency to research posttranslational modifications (eg phosphorylation, glycolization and ubiquitination) as these chemical modifications of proteins often determine protein activity and stability. In the pathogenesis of the tumor, phosphorylation of the amino acid tyrosine occurs in some regulatory proteins as a result of mutation or excessive expression of signal proteins. The traditional approach to posttranslational modification studies involved the purification of this protein, the peptide analysis and the identification of phosphorylated peptide regions by the method of determining the $\mathrm{N}$-terminal sequence. However, mass spectrometry is increasingly used to isolate phosphoprotein-containing peptides from cellular extracts using antibodies specific to phosphotyrosine, followed by identification by MS / MS. The study of these modifications in complex protein mixtures has been improved over the past years thanks to the cation exchange chromatography method, which specifically binds the phosphate group of phosphorylated proteins, and thus the isolated proteins can be identified by the technique MS.

The SELDI-TOF-MS method (surface-enhanced laser desorption ionization - TOF-MS) is a method for detecting markers in various tumors. It is based on the use of different types of protein chips, depending on which protein fraction will be analyzed. The most commonly used chemical chips (anionic, cationic, hydrophobic, hydrophilic, metal ions) and biochemical chips (immobilized antibody, receptor, DNA, enzyme) on which the desired protein from the mixture is retained. After binding of the protein from the mixture to the surface of the chip, a laser directed to them is used, 
the proteins or protein fragments are transferred to the gaseous phase and analyzed in the objectives of the TOF mass spectrometer. This method was important for the detection of numerous diagnostic markers for tumors, as well as for the characterization of a large number of phosphorylated and glycolized proteins and transcription factors $(6,9)$.

The disadvantage of all of the aforementioned methods is that they do not clarify the biological functions of the protein and their role in signaling pathways in malignant tumors. However, for this purpose, protein chips are used which enable the analysis of various signal proteins and their activation state. Based on this approach, information about the type of protein, expression, protein interactions, binding of receptor ligands and enzymatic activity can be obtained (6).

There are two types of protein chips:

1. An analytical protein chip: contains antibodies, antigens or other proteins to determine the amount of labeled proteins in the sample.

2. Functional protein chip: contains a large number of cellular proteins or tissue proteins, various biochemical activities such as protein-protein, protein-lipid, protein-nucleic acid interaction and enzyme-substrate interactions are examined.

After binding of proteins from the mixture onto the chips, if the antibodies are applied, the activated proteins can easily be detected and the activation status of the entire signaling pathways can be determined (for example, because the phosphospecific antibody binds to the phosphorylated protein interacting with the peptide on the chip) (6).

\section{APPLICATION OF PROTEOMICS}

A number of studies have been published on the application of proteomics in clinical practice. In a study on ovarian tumors, a hypothesis was found that pathological changes within the organs reflect the serum proteomic profile and how precisely the serum can be used as a material for early detection of the disease. The authors of the study indicated that pathological changes within the ovaries could be reflected on the proteomic serum profile, which would aim to differentiate neoplastic ovaries from the rest. The authors made a proteomic serum analysis using mass spectrometry. The results showed that the proteomic profile enabled the identification of all 50 patients with cancer. Of the 66 non-malignant samples, as many as 63 , the proteomic profile was recognized. This study has shown that it is possible to apply proteomic methods for the detection of all stages of ovarian tumors (10).

Carcinoma of the breast is one of the carcinoma of very high frequency. An example of breast cancer has revealed that human growth hormone $(\mathrm{hGH})$ is of great importance in the progression of this disease. Namely, growth hormone can be one of the main drivers of the metastasis process. By coagulating the breast carcinoma line MCF-7, it was found that autocrine production of hGH in cells was the driving force of their migration into the surrounding matrix through the process of transforming E-cadherin. Autocrine regulation of hGH in breast cancer was found to be associated with the activation and localization of Pax-5 protein into the nucleus, which is sufficient to induce proliferation of tumor cells. In addition to the importance of autocrine regulation of breast tumors during proteomic research, a number of proteins have been discovered that are important for understanding the molecular basis of breast tumors. It was found that these proteins participate in cell growth, oncogenic progression to cell death processes. Using the protein chips that contain immobilized antibodies on its surface, the activation of the ERBB receptor has been analyzed, which is an important factor in the malignant breast cancer phenotype. Methods of proteomics enabled the thorough investigation of the role and mode of action of the receptor and proteins of this signaling pathway associated with metastasis, progression and poor clinical prognosis of the disease. The proteomic profile of a healthy and malignant breast tissue sample was investigated, with a number of proteins with increased expression found in malignant tissue. Among the other proteins are casein kinases, p53, annexin XI, CDC25C, elF-4E, and MAP kinase 7 , and in malignant tissue decreased expression of the multifunctional regulator 14-3-3e. Using the 2-DEV gel electrophoresis method after which the differential expression proteins are identified by the MS-MS (MALDI-TOF) technique and thanks to this approach in tomoral breast cancer, numerous possible new biomarkers. They include proteins that may be associated with the onset or progression of this disease, which are galectin-1, annexin-5, annexin-1, LDH-B, GST-pi, actin, vimentin, HSP70, CK18 and moezin.

The significance of cytookeratin 19 in cellular events that resulted in severe malignant proliferation of breast cancer cells was also established. A number of proteins significantly related to the metastasis of breast cancer, such as osteopontin and osteonectin, have also been discovered, and it has been found that metalloproteinases of matrix 1 and annexin 1 are associated with the phenotype of non-metastatic cells.

A study conducted on four tumor cell lines, which is basically a common genetic background. These cell lines gradually gained metastatic potential through culture growth. Using the iTRAQ ESI-LC / MS / MS method (isobaric tag for relative and absolute quantification electrospray ionization-liquid chromatography), chan- 
ges were found likely to cause a change in phenotype, and it was found to be protein from the kinase family, phosphatase and some transcriptional factors.

With increased invasiveness of the cells, the expression of SH3GLB1 protein would decrease, and the expression of the protein SUB1, SND1 and TRIM28 increased. Also, multidimensional protein identification methods have identified activity for more than 50 proteins, and up to one third of that number have not been linked to breast cancer until then.

SELDI-TOF (Surface-Enhanced Laser Desorption / Ionization-Time Of Flight) was compared to tumor and healthy tissue, and in this way identified 38 expressed protein expressions (Wdr1, korornin-1 A and p34-Arc) and 15 reduced-expression proteins $(1,11)$.

In patients with urinary bladder carcinoma using proteomic methods in protein analysis in urine samples, psoriasic protein was identified as an early marker of this diseases (6).

\section{THE ROLE OF PROTEOMICS IN TUMOR THERAPY}

Proteomics enable understanding of the molecular basic disease, provides the possibility of early diagnosis of the disease, so it is somewhat understandable that the proteomy will also contribute to the design of a new generation of drugs. Protein profiles can be used as significant markers in diagnosis of the disease, however, a large number of proteins that have a significant role in cellular processes relevant to the development of malignant tumors have still not been detected $(12,13)$.

Radioresistance continues to be a major problem in the treatment of NPC. The molecular mechanisms underlying NPC radioresistance are still unclear, and till now, there have not been effective biomarkers for predicting NPC radiosensitivity. Identification of NPC radioresistance-associated proteins will be helpful for finding biomarkers to estimate NPC response to radiotherapy and deciphering the molecular mechanisms of NPC radioresistance (14).

Proteomic methods increasingly find their place in discovering the early stages of the disease, discovering new targets and biomarkers, and determining the therapy depending on the condition of the patient. Using proteomic methods it is expected that in contrast to the drugs currently used and aimed at one molecular target, in the future, the target will be a whole set of proteins in the signal path $(6,15)$.

The pharmaceutical proteomics can be divided into:

1. Functional proteomics - includes the study of protein interactions, determination of the function and location of protein in the cell, as well as the interaction between proteins between each other and the protein and the DNA and RNA molecules.
2. Expression proteomics - includes protein expression expression. Investigates global changes in the expression of proteins produced in response to internal or some external factor (drug, environmental factors). By comparing proteins expressed in tissue samples or body fluids of healthy individuals compared to samples of patients (serum, plasma, liquor), cell processes and biochemical pathways of proteins that are significant in the onset and progression of the disease can be determined. This is the principle on which the identification of proteins, which would be used as biomarkers of the disease and as potential targets for the drug, would be based (6).

Proteomic tissue analyzes that have been affected by malignant disease have revealed proteins involved in the progression of the disease, and thus contributed to the discovery of potential drug treatment methods. A common problem in the therapeutic approach is resistance to chemotherapy. It is precisely thanks to the proteomic analysis of the cells that are sensitive to the drug in relation to those that are resistant, the identification of a specific resistance marker group is possible, which contributes to the development of new therapeutic approaches and consequently expects a better response of the patient to the administered drug (6).

By detecting the pattern of tumor formation and the network of signaling pathways of the receptors, there is an objection to the question of how to effectively treat tumors. All of this leads us in the time of personalized molecular medicine, where each patient will receive treatment after analysis of the diseased tissue depending on the expression profile of the tumor (1).

\section{CONCLUSION}

Proteomics provides a better understanding of the molecular basis of malignancies, plays a role in the diagnosis of the same, and it is expected to make a significant contribution to the development of new more effective drugs and the development of personalized therapy. Taking into account the importance of malignant diseases, the high rate of their morbidity and mortality, it is clear that the proteomics range can be of great importance and may lead to revolutionary changes in the diagnosis and treatment of malignancies.

\section{DECLARATION OF INTEREST}

The autors declare that there are no conflicts of interests
Abbreviations:
et al. - and others
e.g. - for example 
EGFR - epidermal growth factor receptor

NSCLC - non-small cell lung cancer

LRG1 - leucine rich alpha-2-glycoprotein 1

LMP1 - latent membrane protein 1

EBV - Epstein Barr virus

GPC1 - glypican-1

MIF - migration inhibitory factor

FN1 - fibronectin 1

LAMC1 - laminin gamma 1

HER-2/neu - human epidermal growth factor receptor

CCR6 - human chemokine receptor-6

APC - adenomatous polyposis coli

DKK 4 - dickkopf-related protein 4

CEA - carcinoembryonic antigen

ESI-MS / MS - electrospray ionization tandem mass spectrometry

HPLC - high performance liquid chromatography

\title{
Sažetak
}

\section{IDENTIFIKACIJA NOVIH MOLEKULARNIH BIOMARKERA -PROTEOMIKA}

\author{
Slađana Vujačić \\ Institute for Emergency Medical Services, Podgorica, Montenegro
}

Patogeneza tumora izuzetno je složena i nije je moguće u potpunosti razjasniti postojećim metodološkim pristupima. Proteomika je interdisciplinarna nauka koja se bavi proučavanjem proteina, nosilaca bioloških funkcija organizma. Obuhvata niz metoda za analizu proteina i pruža izuzetne mogućnosti razumevanja molekularne osnove oboljenja, mogućnosti ranog dijagnostikovanja, ali i proizvodnje novih lekova. Proteomske analize tkiva koja su zahvaćena malignim obo-

\section{REFERENCES}

1. Ratkaj I, Kraljević Pavelić S. Istraživanje patogeneze raka dojke uz pomoć metoda proteomike. Medicina Fluminensis. 2009; 45(3): 270-5.

2. Li W, Li C, Zhou T, Liu X, Liu X, Li X et al. Role of exosomal proteins in cancer diagnosis. Mol Cancer. 2017; 16(1): 145.

3. Gonzalez de Castro D, Clarke PA, Al Lazikani B, Workman P. Personalized cancer medicine: molecular diagnostics, predictive biomarkers, and drug resistance. Clin Pharmacol Ther. 2013; 93(3): 252-9.

4. Kraljević Pavelić S, Pavelić K. Novo doba molekularne medicine: dometi proteomike. Medicina Fluminensis. 2009; 45(3): 208-10.

5. Damjanović S, Pe P. Genski markeri karcinoma glave i vrata - savremena saznanja i perspektive. Jugoslov Med Biohem. 2003; 22(4): 273-82. ljenjem otkrile su proteine koji učestvuju u progresiji oboljenja, a samim tim doprineli su otkrivanju potencijalnih metoda za delovanje lekova. Proteomika omogućava bolje razumevanje molekularne osnove ovih oboljenja, ima ulogu u dijagnostici istih, a od nje se očekuje značajan doprinos u razvijanju novih efikasnijih lekova i razvoju personalizovane terapije.

Ključne reči: proteomika, proteini, biomarkeri, tumori.

6. Kraljevic Pavelic S, Saban N. Evolving ž-omics' technologies in the drug development process. Expert Opin Drug Discov. 2007; 2(4): 431-6.

7. Kraljević Pavelić S, Šaban, N. Uloga proteomike u otkrivanju novih protutumorskih lijekova. Medicina Fluminensis. 2009; 45(3): 211-17.

8. Verrills NM. Clinical proteomics: present and future prospects. Clin Biochem Rev. 2006; 27(2): 99-116.

9. Fontana S, De Leo G, Sedic M, Pavelic SK, Alessandro R. Proteomics in antitumor research. Drug Discovery Today: Technologies. 2007; 3(4): 441-9.

10. Petricoin E F, Ardekani A M, Hitt B, Levine PJ, Fusaro VA, Steinberg SM et al. Use of proteomic patterns in serum to identify ovarian cancer. Lancet. 2002; 359(9306): 572-7.

11. Mukhina S, Mertani HC, Guo K, Lee KO, Gluckman PD, Lobie PE.. Phenotypic conversion of human mammary car- 
cinoma cells by autocrine human growth hormone. Proc Natl Acad Sci U S A. 2004; 101(42): 15166-71.

12. Pastwa E, Somiari S. B, Czyz M, Somiari RI. Proteomics in human cancer research. Proteomics Clin Appl. 2007; 1(1): 4-17.

13. Cancer Genome Atlas Research Network. Integrated genomic characterization of endometrial carcinoma. Nature. 2013; 497(7447): 67-73.

\section{Correspondence to/Autor za korespondenciju}

Slađana Vujačić

Institute for Emergency Medical Services

Cvijetna 39/5, Podgorica

sladjanavujacic@yahoo.com
14. Feng XP, Yi H, Li MY, Li XH, Yi B, Zhang PF. Identification of biomarkers for predicting nasopharyngeal carcinoma response to radiotherapy by proteomics. Cancer Res. 2010; 70(9): 3450-62.

15. Lee J M., Kohn E. C. Proteomics as a guiding tool for more effective personalized therapy. Ann Oncol. 2010; 21(suppl 7): 205-10. 